\title{
A Practice Based Behavioral Health Management Registry (BHMR): Implementation, Structure and Content
}

Paul C Langley, PhD

Adjunct Professor, College of Pharmacy, University of Minnesota

\begin{abstract}
Previous commentaries in the Formulary Evaluation section of INNOVATIONS in Pharmacy have pointed to the difficulties of establishing the credibility of trial-based and modeled claims for therapy interventions. Claims for interventions in behavioral health are no exception. A recent report by The Kennedy Forum emphasizes the need for a system of measurement-based care using validated scales to assess the need for and response to therapy. To accomplish this, The Kennedy Forum proposed a core set of outcomes measures for behavioral health interventions. This core set provides the context for a proposed Behavioral Health Management Registry (BHMR). The purpose of this commentary is to describe the structure and content of the BHMR. The BHMR provides access to nine symptom rating scales for depression, mania, anxiety, PTSD, panic attacks, alcohol use, drug abuse and somatization, together with supplementary questions to capture socio-demographic characteristics of patients, pain experience and opioid use, medical marijuana, DSM-V criteria for PTSD diagnosis and sleep experience. As such, with patient and physician inputs over the course of treatment, the BHMR provides an evidence base for physician practices and health care decision makers to evaluate behavioral health interventions by tracking the cumulative response to therapy. In addition, the BHMR captures the perception of the patients as to whether or not their therapy has led to any substantive improvement in activity limitations, symptoms and quality of life. A particular focus of the $B H M R$ is on monitoring and evaluating the impact of interventions on the overall experience of pain as well as tracking pain intensity and functional status by body location. This is important given the prevalence of pain and its association with conditions such as depression and anxiety. The BHMR can also support monthly reports to the practice to summarize patient throughput, the response to care by target pain patients and profiles of opioid use and abuse. The BHMR can be customized to meet the needs of individual practices.
\end{abstract}

Keywords: Behavioral Health Management Registry, BHMR, depression, mania, anxiety, PTSD, panic attacks, drug abuse, chronic pain

\section{Introduction}

A report released by The Kennedy Forum in 2015 Fixing Behavioral Health Care in America pointed to the fact that, although effective treatments exist, many Americans fail to receive the care they need due to 'lack of access, poor quality care and ineffective coordination between medical and behavioral systems' ${ }^{1}$. The specialty mental health care system 'is underequipped to treat the vast number of people with mental health and substance use disorders'. The result is that primary care has become the principal de facto provider of behavioral health care, including substance abuse, with, inevitably, many if not the majority of patients receiving suboptimal care. In the four years since the Kennedy report was issued there appears to be little if any evidence for a substantive revision to the picture presented of the process of care. There is still a significant unmet need for coordination and improvement in care. The primary care focused model proposed by The Kennedy Forum remains central to the

Corresponding author: Paul C Langley, PhD

Adjunct Professor

College of Pharmacy University of Minnesota

Director, Maimon Research LLC

5061 North Apache Hills Trail, Tucson, AZ 85750

Email: langley@maimonresearch.com
Collaborative Care model, which is characterized by a primary care provider leading a team supported by a care manager, is access, in real time, to an evidence base that tracks patient engagement over the course of their treatment and monitors their response to therapy. This population-management perspective implies access to a patient registry where inputs to the registry database are generated by both patients (or their caregivers) and providers. Ideally, a care manager would coordinate inputs to the registry, evaluate responses and work with the care team to deliver effective interventions. At the same time, the registry would provide the basis for report generation, both for the individual patient and the practice. From the latter perspective, reports could be prepared for target patient groups and specific treatment modalities as well as providing a framework for cost-effectiveness assessment. Claims for competing interventions could be evaluated within a meaningful time frame with reports prepared for formulary evaluation.

From a registry perspective, therefore, it is worth noting the following key policy recommendation from the Kennedy report: All primary care and behavioral health providers treating mental health and substance abuse disorders should implement a system of measurement-based care whereby validated symptom rating scales are completed by patients and reviewed by clinicians during encounters. Measurement-based care will help providers determine whether the treatment is working and facilitate treatment adjustments, consultations, or referrals for 
higher intensity services when patients are not improving as expected.

It is also worth emphasizing that measurement based care with the focus on validated PROs is considered best practice in providing optimal care. The ability to track response to therapy has been shown to lead to better outcomes through alerting physicians to possible treatment modifications promptly in real time as well as providing the basis for improved patient engagement.

This is not to suggest, however, that there are not examples of the benefits of collaborative care in behavioral health. A number of these are detailed in the Kennedy report. The point, however, is that while it is possible to identify funded collaborative care interventions, the outreach is limited. The overwhelming majority of behavioral health (and physician groups together with specialist pain clinics) are not involved in measurement-based care, let alone collaborative care. The potential is limited because the opportunities are not in place to create financial incentives to facilitate creating a practicebased registry to support measurement-based care

The purpose of this commentary, given the recommendations of the The Kennedy Forum, is to propose a structure and associated metrics for a behavioral health registry: the Behavioral Health Management Registry (BHMR).

\section{Response Metrics}

The key to an effective registry is the choice of response metric that is built into the registry. As the Kennedy report points out 'The reality is that for many systems of care, the usual practice does not include regular use of validated and quantifiable rating scales'. This requirement has been recognized in two recent registry proposals detailed in commentaries published in INNOVATIONS in Pharmacy for medical marijuana dispensaries and the treatment of chronic pain 234 . These proposed registries emphasize the critical role validated patient reported outcomes (PRO) instruments can play in monitoring outcomes. In the case of chronic pain the registry structure included not only overall pain assessments, for example chronic pain evaluations, but also validated instruments targeted to specific pain locations to assess the impact of therapy on pain intensity and functional status. At the same time, with the prevalence of opioids in chronic pain, the registry captured risk assessments for medication abuse, attitudes to medications as well as instruments to capture the impact of pain interventions on high prevalence co-morbidities such as depression and anxiety.

The proposals for chronic pain and medical marijuana registries recognize, not only the increasing focus on outcomes as opposed to process measures by agencies such as CMS, but the fact that the evidence base to support intervention choice is limited. In the case of medical marijuana, with the possible exception of severe epilepsy, the evidence base, judged against graded evidence standards, is essentially non-existent.
Evidence for non-cancer pain in the medium and long-term is also limited. The latest CDC Guidelines for Prescribing Opioids for Chronic Pain point out that evidence on long-term opioid therapy for chronic pain outside of end-of-life care remains limited, with insufficient evidence to determine long-term benefits versus no opioid therapy ${ }^{5}$. Although clinical trial data would suggest that risk for serious harms appear to be dose dependent, the evidence is typically short-term with most trials only reporting outcomes for 12 weeks or less. At best, the evidence would suggest that opioids are only moderately effective for pain relief and with small benefits for functional outcomes. This criticism applies with equal force to established opioid formulations as well as to the abuse deterrent opioid formulations that are entering the market place. Formulary committees cannot judge the competing merits claimed for abuse deterrent formulations in the absence of credible evidence, both from randomized clinical trials (RCTs) as well as practice based observational studies.

There is, in the case of behavioral health, with the focus on mental health and substance abuse, considerable overlap in choice of metric with chronic pain. More importantly, and this is a feature of behavioral health interventions that is often overlooked, a substantial number of patients present with chronic non-cancer pain. The association of chronic pain with depression and anxiety is well established and it was for this reason that these potential co-morbidities were captured in the CPMR.

\section{Resources and Incentives}

A first step towards a more effective delivery of behavioral health services by specialist physician practices in co-ordination with other specialist providers, is to recognize the importance of incentives. With financial pressures on health care delivery, providers may reasonably argue that while a registry concept at the practice level has merit, there are insufficient resources available to support implementation. These could involve resources to proactively outreach to patients to support engagement and compliance in generating reports to track response to therapy as well as resources within the practice to support registry data entry and practice level reporting.

If a practice is to adopt a registry platform then there has to be a prior assessment of the implications of this for practice management and the allocation of resources within that practice. If, for example, providers within the practice believe that a registry incorporating validated instruments can provide a more rigorous framework for treatment decisions and response monitoring, then they need to be assured that these more comprehensive and complex assessments can be resourced appropriately. In, for example, a fee-for- service environment where the primary revenue stream is from CPT billing to both Medicare/Medicaid and private insurers. The option of adopting a registry to support treatment decisions offers the practice the opportunity to-reassess how resources 
might be more optimally assigned to target patient groups consistent with billing criteria.

Again, in a fee-for-service environment, a critical measure of resource allocation would be the CPT billing profile as this is the primary determinant of the practice revenue stream. While this may be augmented by other revenue programs, notably those focused on the Medicare population (e.g., MIPS) the practice has to consider the opportunities for reimbursement where more detailed, comprehensive and time consuming patient encounters are considered justified.

It is not the purpose here, however, to make any suggestions as to the appropriate billing arrangements. It is up to the practice, in consultation with their medical billing agency or their own billing staff to determine the possible options.

The fact that the BHMR provides a platform for a behavioral health practice to evaluate resource allocation in its attempts to monitor and evaluate response to therapy, should not be seen as a vehicle for an across-the-board CPT up-coding. The principal focus of the BHMR is on tracking response to therapy. The emphasis is on duty of care. The presumption is that access to a structured registry environment provides treating physicians with tools that can support defensible and medically necessary treatment decisions. To achieve this a practice needs the resources to devote to possibly more time-intensive yet evidence driven patient care; a personalized medicine platform.

\section{Behavioral Health Management Registry}

The proposed Behavioral Health Management Registry (BHMR) adopts a structure similar to that proposed for chronic pain and medical marijuana. The BHMR is practice focused and, in the first instance is designed to be adopted by behavioral health practices. That is, the structure incorporates selected PROs specific to behavioral health, supplemented by PROs specific to high prevalence co-morbidities in behavioral health practice (e.g., chronic pain) where the practice may intervene in its own right or refer patients for more specialized and intensive interventions. At the same time, inputs from the practice provider are designed to complement the PROs. The registry captures diagnosis (ICD-10-CM) codes, together with CPT codes specific to each visit made to the practice.

\section{Choice of Metrics}

There are a number of competing PROs for all conditions typically treated in a behavioral health practice. In the present case the task of selecting the appropriate PRO was made simpler by the Kennedy Foundation proposed 'core set' of validated outcome measures ${ }^{6}{ }^{7}$. The outcome measures selected for the registry cover the following domains:

- Depression

- Fatigue

- Mania

- Anxiety

- PTSD (Post Traumatic Stress Disorder)
- Panic attacks

- Alcohol

- Drug abuse

- Somatization

At the same time, the BHMR offers options for evaluating patients in more detail. Providers have the options of downloading a number of validated instruments for assessing both the presence of comorbid conditions as well as a more indepth assessment of the patient to confirm a provisional hypothesis. These cover:

- Pain experience and likelihood of chronic pain

- Pain intensity and functional status by pain location

- Attitudes to pain medications

- Opioid use and abuse risk

- Constipation

- Medication abuse (in course of treatment)

- Medical marijuana use

- Confirmatory PTSD evaluation

- Sleep experience

\section{Pain Experience and Medication Abuse}

The association of pain with depression, together with the associated conditions of fatigue and anxiety is well established, together with its the impact on mood, appetite and sleep.. The role of behavioral health in addressing pain and its symptomology is recognized with the application of cognitive behavioral therapy and stress reduction therapy. These strategies may be applied as part of a pain management strategy that includes pharmacotherapy, including opioid prescribing.

It is an open question, however, as to how well the experience of pain is assessed in behavioral health practices, to include the likelihood or continuing chronic pain and the baseline status and response of patients to behavioral therapy interventions by pain location.. There is little evidence for the application of validated instruments, not only to track response to therapy targeted at pain experience, but also to apply validated instruments to assess therapy responses that may be comorbid with pain, notably depression, anxiety, fatigue and sleep.

To the extent that behavioral health practices rely on or supplement interventions with pain medications, it is important to provide, using validated instruments, an assessment of attitudes to pain medications, recent and current opioid use and an assessment of the likelihood or medication, in particular opioid abuse. At the same time, there needs to be an ongoing review of likely medication abuse by the patient.

The recommendation by The Kennedy Forum is for the DAST-10 instrument to be used to assess the patient's potential for drug abuse, where abuse is defined as the use of prescribed or over the counter medications or drugs in excess of usage directions 8 . While the DAST-10 has wide recognition, it was decided that as this instrument requires licensing and fee payments that 
alternative instruments should be considered. To evaluate the potential for abuse, particularly in respect of pain medications it was decided to include, as default PROs, two instruments selected for the CPMR. These instruments are: (i) the shortform Pain Medication Attitude Questionnaire (PMAQ-14) and (ii) the Brief Risk Questionnaire (BRQ) ${ }^{9}$. Given the ability to customize the BHMR, it is at the discretion of the user to include the DAST-10 in preference to the PMAQ-14 and the BRQ.

The original 78-item version of the PMAQ developed by McCracken et al addressed seven areas of patient concern: addiction, perceived need, unfavorable scrutiny by others, adverse side effects, tolerance, mistrust in the prescribing doctor and withdrawal ${ }^{10}$. The short-form (PMAQ-14) proposed by Elander et al captured from the original 2 items from each of the seven PMAQ scale while retaining the content of the original scales. Confirmatory factor analysis demonstrated that the PMAQ-14 retained the original 7-factor structure with correlation analysis demonstrating that it retained the validity of the original constructs.

As well as capturing attitudes to medications, the CPMR also addressed the question of the risk for prospective medication aberrant behavior. A number of risk assessment instruments were reviewed. These included the Pain Medication Questionnaire (PMQ), the Screener and Opioid Assessment for Patients with Pain - Revised (SOAPP-R; 5, 14 and 24 item versions), the Opioid Risk Tool (ORT) and, most recently, the Brief Risk Questionnaire (BRQ) ${ }^{11} 121314$.

The $B R Q$ is designed to predict opioid misuse, abuse, addiction and diversion. It was chosen in preference to other risk assessment instruments, specifically the Opioid Risk Tool (ORT) and the Screener and Opioid Assessment for Patients with Pain - Revised (SOAPP-R), because, on evidence available it is overall the most accurate with a sensitivity of $80 \%$ and a specificity of $41 \%$. Sensitivity in this context is the ability to identify those patients who later were observed to engage in opioid or medication misuse. The sensitivity of the $B R Q$, which is best seen not as a 12-item overall assessment of risk but as an evaluation of 12 areas of risk, also compared favorably in a head-to-head comparison with the structured clinical Brief Risk Interview (BRI) ${ }^{15}$.

\section{Medical Marijuana}

It is also important to evaluate the role of botanical cannabis in patients being treated for behavioral health conditions. There is a limited and often conflicting evidence for the selfmedicating use of botanical cannabis in conditions such as depression, anxiety and PTSD. Of concern is the evidence for adverse psychiatric outcomes. In a recent review, for example, the authors conclude that the "known risks of marijuana ... currently outweigh (the) unknown benefits for PTSD' ${ }^{16}$.

Given the uncertainties in the benefit-risk ratio of botanical cannabis in behavioral health, it is important to assess the experience of patients with botanical cannabis, whether it be sourced as part of a medical marijuana program certified by other providers or whether it is self-medicated. As well, it is important to assess the form of administration and dosing. These elements are also captured by the BHMR.

\section{Post-Traumatic Stress Disorder}

The PTSD checklist in the registry (PCL-5) is for DSM-V symptoms designed to assess provisionally the likely presence of PTSD ${ }^{17}$. This is different from the PRO recommended in the Kennedy report which is based on the symptoms captured in the DSM-IV. Given changes to the number and description of symptoms, together with the revised scoring scale, the PCL-5 scores are not compatible with the DSM-IV scoring. This 20item validated scale, scored on a 5-point interval, is designed to give a provisional diagnosis of PTSD. It is not a stand-alone diagnosis and should be supplemented by a clinical assessment with a structured interview (e.g., the clinician-administered PTSD scale for DSM-V, CAPS-5 together with the Life Events Checklist) ${ }^{18}$. The instrument is designed for symptoms in the past month and changes in these symptoms over time. Endorsed symptoms are those scored 'moderately' or higher.

The PCL-5 can determine a provisional diagnosis in two ways: (i) DSM-V diagnostic rule where with at least 1 symptom from criterion B (questions 1 -5); 1 criterion $\mathrm{C}$ item (questions 6-7); 2 criterion $D$ items (questions 8-14) and 2 criterion $E$ items (questions 15-20) or (ii) summing all items and using a cut-off score of 33. Change scores for the PCL-5 have yet to be determined. As a reference point, the DSM-IV PCL instrument suggests a minimum threshold of 5 points as determining response to therapy, with 10 points suggesting the change is clinically meaningful.

\section{The BHMR Platform: Reporting Structure}

The BHMR comprises two set of reports: one set completed by the patient the other by the provider's office. These are an Initial Visit Patient Report completed on-line by the patient either prior to or at their first provider visit together with an Initial Visit Patient Summary Report which scores and summarizes patient responses to the Initial Visit Report. Following the first visit, the patient completes a Patient Satisfaction and Management Plan Report. For all subsequent visits over the course of treatment, this process is repeated. The patient completes an on-line Follow-up Visit Report prior to the visit, with a scored Follow-up Visit Patient Summary Report sent to the provider, followed by a Patient Satisfaction Report that is retained within the registry but only provided to the practice as a monthly de-identified report for all initial visit respondents.

Following each provider visit, the practice completes an Initial Visit Practice Report and for all subsequent visits a Follow-up Visit Practice Report. These reports are entered directly into the registry by the practice following each visit, complementing the monitoring and audit trail created by the patient visit reports. Initial Visit Patient Report 
The Initial Visit Patient Report platform captures the 9 validated PROs recommended in the Kennedy report. These are detailed in Table 1. At the same time, the BHMR offers, at the discretion of the provider, a further 10 validated PROs to detail pain experience and functional status by body location, opioid use potential abuse, PTSD and sleep.

Table 1

Core BHMR PRO Instruments

\begin{tabular}{|c|c|c|}
\hline Symptom or Comorbidity & Comorbidities and Symptoms & Score \\
\hline Somatization & PHQ-15 Somatization Scale ${ }^{19}$ & $\begin{array}{l}\text { Each item on the } \mathrm{PHQ}-15 \text { is rated on a } 3 \text {-point scale }(0=\text { not bothered at } \\
\text { all; } 1=\text { bothered a little; } 2=\text { bothered a lot). The total score can range } \\
\text { from } 0 \text { to } 30 \text {, with higher scores indicating greater severity of somatic } \\
\text { symptoms. }\end{array}$ \\
\hline Fatigue & Fatigue Severity Scale 2021 & $\begin{array}{l}\text { Single score as average of } 9 \text { items; presence of fatigue } \geq 4 \text {. Note: mean } \\
2.3 \text { (SD }+/-0.7 \text { in normal healthy adults) }\end{array}$ \\
\hline Depression & PHQ-9 Depression Scale ${ }^{22}$ & $\begin{array}{l}\text { Score range } 0-27 \\
\text { Minimal Depression (score } 0-4) \\
\text { Mild Depression (score } 5-9 \text { ) } \\
\text { Moderate Depression (score } 10-14 \text { ) } \\
\text { Moderately severe depression (score } 15-19 \text { ) } \\
\text { Severe Depression (score } 20+\text { ) }\end{array}$ \\
\hline Anxiety & GAD-7 Anxiety Scale ${ }^{23}$ & $\begin{array}{l}\text { Score range } 0-28 \\
\text { None or very mild anxiety (score } 0-4) \\
\text { Mild anxiety (score } 5-9) \\
\text { Moderate anxiety }(10-15) \\
\text { Severe anxiety }(16+)\end{array}$ \\
\hline Mania & $\begin{array}{l}\text { Altman Self-Rating Mania } \\
\text { Scale }{ }^{24}\end{array}$ & $\begin{array}{l}\text { Comprises } 5 \text { sub-scales to cover (i) positive mood; (ii) self-confidence; } \\
\text { (iii) sleep patterns; (iv) speech, ( } v \text { ) activity level. Each subscale scored } \\
\text { from } 1 \text { = baseline to } 5 . \text { A combined score of } 6+\text { indicates a high } \\
\text { probability of mania. }\end{array}$ \\
\hline Panic Attacks & $\begin{array}{l}\text { Panic Disorder Severity Scale } \\
25\end{array}$ & $\begin{array}{l}\text { The PDSS consists of seven items, each rated on a 5-point scale, which } \\
\text { ranges from } 0 \text { to } 4 \text {. The items assess panic frequency, distress during } \\
\text { panic, panic-focused anticipatory anxiety, phobic avoidance of } \\
\text { situations, phobic avoidance of physical sensations, impairment in } \\
\text { work functioning, and impairment in social functioning. The overall } \\
\text { assessment is made by a total score, which is calculated by summing } \\
\text { the scores for all seven items. The total scores range from } 0 \text { to } 28 \text {. A } \\
\text { score of } 9+\text { suggests the need for a formal diagnostic assessment. }\end{array}$ \\
\hline $\begin{array}{l}\text { Post-traumatic Stress } \\
\text { Disorder }\end{array}$ & PCL-5 Checklist for PTSD & $\begin{array}{l}\text { A } 20 \text {-item stress symptom check list with each item scored } 0=\text { not at } \\
\text { all to } 4=\text { extremely. Scored either according to DSM- } 5 \text { criteria by } \\
\text { minimum number of items from each subscale or a cut-off of } 33+\text { for } \\
\text { the aggregate raw score } 0-80 \text {. }\end{array}$ \\
\hline Alcohol Use & Audit-C Alcohol Screen ${ }^{26}$ & $\begin{array}{l}\text { A 3-item short version of AUDIT } 10 \text { item questionnaire to identify } \\
\text { hazardous drinkers or those with active alcohol disorders. Scored on } \\
\text { scale } 0 \text {-12. For males a score of } 4+\text { is considered positive (females } 3+\text { ). }\end{array}$ \\
\hline Drug Abuse & $\begin{array}{l}\text { Drug Abuse Screening Test } \\
\text { (DAST-10) (optional) }\end{array}$ & $\begin{array}{l}\text { A } 10 \text {-item self-report instrument to assess involvement with drugs in } \\
\text { past } 12 \text { months (not alcohol). Scores from } 0 \text { (no problems reported) t0 } \\
9-10 \text { severe and suggested intensive assessment. }\end{array}$ \\
\hline Drug Abuse (Attitude) & $\begin{array}{l}\text { Pain Medication Attitude } \\
\text { Questionnaire - short form } \\
\text { (PMAQ-14 }\end{array}$ & $\begin{array}{l}\text { A short form of the 78-item PMAQ instrument. Retains the original } 7 \\
\text { subscales: addiction, perceived need, unfavorable scrutiny by others, } \\
\text { adverse side effects, tolerance, mistrust in the prescribing doctor and } \\
\text { withdrawal }\end{array}$ \\
\hline
\end{tabular}




\begin{tabular}{|l|l|l|}
\hline Drug Abuse (Opioids) & Brief Risk Questionnaire (BRQ) & $\begin{array}{l}\text { A 12-item instrument based on the BRI to predict opioid misuse, abuse, } \\
\text { addiction and diversion of opioids - a broader array of behaviors than } \\
\text { only predicting opioid addiction. }\end{array}$ \\
\hline
\end{tabular}

The data elements and symptoms captured in the Initial Visit Patient Report are:

- Socio-demographic status

- Education level

- Employment status

- Current and previous overall health

- Somatization (PHQ-15)

- Fatigue (Fatigue Severity Scale)

- Depression (PHQ-9)

- Anxiety (GAD-7)

- Mania (Altman Self-Rating Mania Scale)

- Panic Attacks (Panic Disorder Severity Scale)

- Post-Traumatic Stress Disorder (PTSD)

- Stress Experience

- Stress problems ( $\mathrm{PCL}-5)$

- Alcohol Use (AUDIT-C)

- Attitudes to medications

- Likelihood of opioid abuse

Initial Visit Patient Summary Report

Once the patient has completed the report, it is immediately summarized and scored to create the Patient Initial Visit Summary Report. This is sent directly as a PDF report to the provider with a copy retained as part of the registry. The report can be accessed by the patient if required. The summary report scores the PRO instruments detailed in Table 1 establishing a baseline for subsequent visit scores to establish response to therapy. Wherever possible the provider is informed as to whether or not any change in reported scores over baseline is considered clinically significant.

\section{Patient Satisfaction and Management Plan Report}

Following the initial visit the patients completes a Patient Satisfaction and Management Plan Report. This report follows from a similar report included as part of the CPMR. The satisfaction with care component covers:

- Provider: satisfaction with care provided (thoroughness, time spent, overall quality of care)

- Other Staff: satisfaction with care provided (reception staff, courtesy)

- Practice Access: satisfaction with access provided (contacting office, waiting in office, parking)

In each case, responses are on a five-point scale: excellent, good, just satisfactory, fair or poor.

In addition, the patient completes after the initial visit a series of questions on the extent to which a behavioral health management plan has been provided and whether specific issues (e.g., fatigue, anxiety, depression, sleep) have been addressed. The patient is told that: $A$ behavioral health management plan is a proposal for how your concerns are to be addressed; it might involve a proposal for a management team involving other specialist providers and nursing support, treatment options and possible use of pharmaceuticals, a timeline for treatment and the outcomes sought.

The specific questions are:

- Did your provider discuss and agree a treatment management plan with you?

- Did your provider explain the importance of monitoring your response to therapy through continuing to report your health status on-line?

- Did your provider discuss the possible involvement of other health professionals in your treatment?

- Did your provider assess and recommend treatment for specific conditions identified in the initial evaluation of your health status (e.g., depression, anxiety, fatigue, panic attacks)?

- Did your provider review possible prescription medication use as part of your management plan?

- If the treatment of severe or chronic pain is part of your management plan, did your provider undertake a comprehensive assessment of pain status, to include pain intensity by body location and functional status?

- Did your provider review the risks and benefits for you of proposed medication use?

- Did your provider discuss the possible use of opioids in your treatment?

- Did your provider caution you on the abuse potential of opioids?

- If opioids were recommended, did your provider ask you to complete an opioid agreement?

- Did your provider review the possibility of medical marijuana as part of your treatment management plan?

- Did your provider discuss what the side effects of your treatment might be?

- If you are not at work, did you discuss with your provider the possibility of returning to work?

Initial Visit Practice Report

Following the first encounter with the patient, the practice completes an on-line Initial Visit Practice Report. This report is designed to ensure: (i) that the registry captures those data that are entered in the CMS 1500 form or its equivalent; (ii) that medication use is reported accurately; and (iii) that the registry captures medication change or discontinuation and reasons for treatment discontinuation. 
The data elements captured in the Initial Visit Practice Report are:

- ICD-10-CM diagnosis codes

- $\quad$ CPT codes

- Therapy intervention(s)

- Adverse Events

- Medication utilization

- Generic/brand name

- Dose

- Frequency

- NDC code

- Response to therapy

- Referrals

- Discontinuation of therapy

\section{Follow-up Visit Patient Report}

Prior to each follow-up visit, the patient completes a report to track the response to therapy. This report is shorter than the initial visit report as it captures only: (i) employment status and (ii) those PRO instruments for which a preliminary diagnosis has included the symptoms addressed: these are: (i) mania; (ii) panic attacks; and (iii) PTSD. The report also excludes attitudes to medications and the likelihood of opioid abuse.

The Follow-up Visit Patient Report includes two questions which are repeated for all subsequent reports. These are: (i) reports of medication abuse and (ii) the patient assessment of response to therapy. In the former case, the patient reports on activities that are associated with medication abuse behavior. These are identical to those utilized in the CPMR. In the latter case, the PRO is the Patient Global Impression of Change (PGIC) instrument. This instrument is used widely in phase 3 clinical trials and is a useful counterpoint to physician assessed response to therapy through validated PROs or simply professional assessment.

\section{Follow-up Visit Patient Summary Report}

Following all subsequent visits over the course of therapy, the responses to the Follow-up Visit Patient Report are scored and summarized for the provider. Again, they are captured in the registry with copies available on request to the patient. Importantly, the report also reports change in reported scores over baseline. This is a key input to assessing response to therapy. This format follows from that adopted by the CPMR.

\section{Follow-up Visit Practice Report}

The Follow-up Visit Practice Report is identical to the Initial Visit Practice Report with the exception of questions on response to therapy and reasons for therapy discontinuation. This retains a consistent or standardized response although the input may change (e.g., referrals, therapy modification)

\section{Supplementary Treatment Assessments}

As noted above, the BHMR allow the provider to assess therapy response at a more granular level with supplementary treatment evaluations. In this version of the BHMR the focus is on: (i) pain experience; (ii) medical marijuana; (iii) PTSD; and (iv) sleep. In each case, the core BHMR platform allows the provider/patient either in an office environment or through an on-line link to access validated instruments and/or provide links to other registries.

\section{Pain Experience}

In large part because of the likelihood that a proportion of patients may report pain at more than one body location together with the difficulty of establishing prior experience with pain levels and pain locations, the BHMR, following the earlier CPMR, adopts a two-stage approach in evaluating baseline pain experience at the initial visit.

In the first stage, patients are asked to detail their overall current pain experience together with their long-term experience of pain together and an assessment of their likelihood of their continuing to experience chronic pain. Current pain experience is defined in terms of (i) current pain on a standard visual analogue scale (VAS) where $0=$ no pain and 10 = pain as bad as it could be; (ii) worst pain (VAS scale) in past two weeks; and (iii) average pain (VAS scale) over the past two weeks. These scores are combined to give a 'pain intensity' score. Patients then report their prior experience of chronic pain and the impact of their pain experience in the past six months on their activity status utilizing the validated Chronic Grade Pain Scale (CGPS) instrument ${ }^{27}$. This yields two categories of pain and disability and two categories of disability and its limiting effects. Finally, in this section, the algorithm proposed by Von Korff and Dunn is applied, with supplementary questions, to yield a risk score for the likelihood of continuing chronic pain ${ }^{28}$.

In the second stage, the focus is on pain intensity and functional status by body location. The BHMR, following the CPMR, identifies 13 pain locations and uses, where feasible, validated instruments to assess baseline pain intensity and functional status, tracking this over the course of treatment. In some cases the instrument only identifies functional status and, where this occurs, supplementary questions to measure pain intensity are included. This format provides the framework for tracking response to therapy.

The BHMR, again following the CPMR also addresses the question of the likelihood of the patient experiencing neuropathic and fibromyalgic pain. Although a clinical diagnosis for neuropathic pain is the 'gold standard' a number of instruments have been proposed as symptom-based screening questionnaires for neuropathic pain. These instruments include the Self-completed Douleur 
Neuropathique 4 (S-DN4) ${ }^{29}$, the ID-Pain ${ }^{30}$, the pain detect questionnaire (PDQ) 31 and the Self-completed Leeds Assessment of Neuropathic Symptoms and Signs (S-LANSS) ${ }^{32}$. For the purpose of the CPMR, the instrument selected was the ID-Pain with 6 sensory description items. The ID-Pain is short, it does not involve any patient self-examination and psychometrically it performs as well as the S-DN4 and PDG, and better than the S-LANSS ${ }^{33}$. Similarly, in the case of possible fibromyalgia, the patient is asked to report on the pain experience across multiple locations. Again, this is only indicative and is not a substitute for a clinical assessment. In the case of scores for hip pain, leg pain and foot or heel pain the assessment is in terms of (i) response to an item list (13) to give assessment of status by item but no overall score and (ii) pain intensity at present time, worst in previous two weeks and average over past two weeks. Again, there is the option for a client to choose a specific measures of pain and functional status for hip, leg or foot/heel pain (e.g., Oxford Hip Score ${ }^{34}$ )

Table 2 details the 13 pain locations and the validated instrument that is proposed to assess functional status and, unless supplemented by a pain intensity score, the pain level reported. Scores are presented in the patient summary and sent to the provider both for the aggregate score as well as scores categorized to grade levels and subscales. As constipation is a common side effect of opioids, the provider has the option of utilizing the PAC-SYM questionnaire to monitor constipation experience and concerns.

Table 2

BHMR Pain Locations and Validated Instruments for Assessing Pain, Functional Status and Constipation

\begin{tabular}{|c|c|c|}
\hline Pain Location & Instrument & Score \\
\hline Head Pain & $\begin{array}{l}\text { Migraine Disability Assessment Score } \\
\text { (MIDAS) }{ }^{35}\end{array}$ & $\begin{array}{l}\text { Grade 1: Little or no disability (score } 0-5 \text { ) } \\
\text { Grade 2. Mild disability (score } 6-10) \\
\text { Grade 3: Moderate disability (score } 11-20 \text { ) } \\
\text { Grade 4: Severe disability (score } 21+\text { ) }\end{array}$ \\
\hline Orofacial Pain & $\begin{array}{l}\text { Manchester Orofacial Pain and Disability } \\
\text { Scale }{ }^{36}\end{array}$ & $\begin{array}{l}\text { Physical Disability (score 0-14; } 0=\text { least disability) } \\
\text { Psychosocial Disability (score } 0-38 ; 0=\text { least disability) } \\
\text { Aggregate (score } 0-52 \text { ) }\end{array}$ \\
\hline Neck or Cervical Pain & $\begin{array}{l}\text { Copenhagen Neck Functional Disability } \\
\text { Scale }{ }^{37}\end{array}$ & $\begin{array}{l}\text { Aggregate score }(0-30 ; 0=\text { no real complaints to } 30= \\
\text { real disability) }\end{array}$ \\
\hline Shoulder Pain & $\begin{array}{l}\text { Shoulder Pain and Disability Index } \\
\text { (SPADI) }\end{array}$ & $\begin{array}{l}\text { Aggregate score, total pain score and total disability } \\
\text { score each as a percentage. Minimum detectable } \\
\text { change } 13 \text { points ( } 90 \% \text { confidence) }\end{array}$ \\
\hline Elbow Pain & Patient-Rated Elbow Evaluation (PREE) 39 & $\begin{array}{l}\text { Pain subscale and Function subscales with total score } \\
\text { with pain and functional problems weighted equally } \\
\text { on a scale of } 100 \text { ( } 0=\text { no disability })\end{array}$ \\
\hline Wrist or Hand Pain & $\begin{array}{l}\text { Patient- Rated Wrist Hand Evaluation } \\
\text { (PRWHE) }\end{array}$ & $\begin{array}{l}\text { Pain score }(0=50), \text { Function score }(0-50) \text { and total } \\
\text { score }(0=\text { best score; } 100=\text { worst score })\end{array}$ \\
\hline Mid-back or Thoracic Pain & Roland Morris Disability Scale 4142 & Score $0-24$ (score $\geq$ poor outcome) \\
\hline Lower-back or Lumbar Pain & Roland Morris Disability Scale & Score $0-24 ;$ (score $\geq$ poor outcome) \\
\hline Hip Pain & Items only & No validated aggregate score or subscales \\
\hline $\begin{array}{l}\text { Lower Abdominal Pain } \\
\text { (Males) }\end{array}$ & $\begin{array}{l}\text { NIH-CPSI Abdominal Pain } \\
\text { Questionnaire }^{43}\end{array}$ & $\begin{array}{l}\text { Pain: score } 0-21(0=\text { least pain }) \\
\text { Urinary Symptoms: score } 0-10(0=\text { no problem }) \\
\text { Quality of Life: score } 0-12(0=\text { no impact })\end{array}$ \\
\hline $\begin{array}{l}\text { Lower Abdominal Pain } \\
\text { (Females) }\end{array}$ & NIH-CPSI Abdominal Pain Questionnaire & $\begin{array}{l}\text { Pain: score } 0-21(0=\text { least pain }) \\
\text { Urinary Symptoms: score } 0-10(0=\text { no problem }) \\
\text { Quality of Life: score } 0-12(0=\text { no impact })\end{array}$ \\
\hline Knee Pain & $\begin{array}{l}\text { International Knee Documentation } \\
\text { Committee (IKDC) Questionnaire: } 2000 \\
\text { Subjective Knee Evaluation Form }{ }^{44}\end{array}$ & $\begin{array}{l}\text { Summing score ( } \max 87 \text { ) to give percentage. Score } 100 \\
\text { no limitations. }\end{array}$ \\
\hline Leg Pain & Items only & No validated aggregate score or subscales \\
\hline Foot or Heel Pain & Items only & No validated aggregate score or subscales \\
\hline Constipation & PAC-SYM Questionnaire ${ }^{45}$ & $\begin{array}{l}\text { Score averaged over } 11 \text { items (range } 0-4 \text { ) } \\
\text { Average or mild constipation (score } 0-0.9 \text { ) } \\
\text { Moderate constipation (score } 1.0-2.9 \\
\text { Severe or very severe constipation (Score 3.0+) }\end{array}$ \\
\hline
\end{tabular}




\section{Medical Marijuana}

The extent to which behavioral health interventions might consider botanical cannabis as a treatment option is not known. Providers may consider specific formulations of botanical cannabis as an option for opioids although, as noted in an earlier series of commentaries, the evidence base for botanical cannabis in the core behavioral domains is limited. If botanical cannabis is considered then the provider would have to support the patient's application for a medical marijuana card as well as recommending a dispensary that provided feedback to the provider on dosing regimen, form of administration and response to therapy. Few dispensaries, if any, are in a position to provide such feedback.

Rather than relying upon feedback from a dispensary, the BHMR allows the provider access to a self-reporting series of questions that the patient completes after each dispensary visit. These details:

- Name of dispensary

- Visit date

- Dosing (purchase)

$\begin{array}{ll}\circ & \text { Cannabis Strain/Brand name } \\ \circ & \text { THC mg/day } \\ \circ & \text { CBD mg/day } \\ \circ & \text { THC \% } \\ \circ & \text { Frequency of administration (day) }\end{array}$

- Administration

$\begin{array}{ll}\circ & \text { Smoking } \\ \circ & \text { Vaporization } \\ \circ & \text { Tinctures } \\ \circ & \text { Ingestible oil } \\ \circ & \text { Edible } \\ \circ & \text { Topical }\end{array}$

Post -traumatic Stress Disorder

Although to PCL-5 can be utilized to report ongoing response to PSTD treatment, the diagnosis provided by the PCL-5 score is only a provisional one. For providers who wish a more conclusive evaluation of PTSD the BHMR provides access to two instruments that can be downloaded for a detailed assessment. These are the CAP-5 and the LEC-5, reporting those results both as a checklist and summary scores for the registry. Reporting on the CAP-5 summary sheet gives an added dimension to evaluating treatment response to PTSD over the treatment timeframe. The DSM-V Criterion A items captured in the CAP-5 clinical interview target the onset and duration of symptoms, subjective distress, impact of symptoms on social and occupational functioning, improvement in symptoms since a previous CAPS administration, overall response validity, overall PTSD severity, and specifications for the dissociative subtype (depersonalization and derealization). The CAP-5 downloaded for administration in the physician office, together with the LEC-5. This latter report asks respondents to detail their stressful experience(s) and to indicate whether or not they witnessed or learned about it. Respondents are then asked to detail the single or worst event.

\section{Sleep Experience}

Although sleep experience is not considered a core domain, sleep experience is addressed in a number of items captured in the validated core instruments. If the provider wishes to assess sleep experience in more detail, a link is provided to the Rand Sleep scale. This asks patients: (i) time taken to fall asleep; (ii) hours of sleep and (ii) sleep patterns over the previous two weeks.

\section{Conclusions}

Evaluating and treating patients in the area of behavioral health is both time consuming and resource intensive. The implications of a long-term engagement between patient and provider point, as The Kennedy Forum emphasizes, the importance of a structured and validated assessment of patients and tracking of patient outcomes. Unless the practice can be recompensed by a revenue stream that supports a more intensive and evidence driven evaluation this will not occur. As recommended by the Kennedy Forum, the acceptance of validated instruments to support and monitor treatment decisions provides the opportunity for the practice providers to allocate the time to evaluate, develop management plans and monitor response to therapy. This is the role of the BHMR: to support the provision of more indepth and rigorous documentation in the duty and process of care.

Conflicts of Interest: None declared 


\section{References}

${ }^{1}$ The Kennedy Forum. Fixing Behavioral Health Care in America. 2015
http://thekennedyforum-dot-org.s3.amazonaws.com/documents/KennedyForum-BehavioralHealth FINAL 3.pdf

2 Langley PC. Outcomes, registries and medical marijuana: Towards establishing dispensary monitoring and reporting standards. Inov Pharm. 2018;9(4):No.7

${ }^{3}$ Langley PC. Establishing credibility for medical marijuana: The proposed Prometheus Dispensary Registry for botanical cannabis. Inov Pharm. 2019;10(1):No. 2

${ }^{4}$ Langley PC. A practice based chronic pain management registry (CPMR): Structure and content of a proposed platform Inov Pharm. $2019 ;$ 10(1): Article 11

${ }^{5}$ Dowell D, Haegerich TM, Chou R. CDC Guideline for Prescribing Opioids for Chronic Pain - United States, 2016. MMWR Recomm Rep. 2016; ePub: March 2016: DOI: http://dx.doi.org/10.15585/mmwr.rr6501e1er

${ }^{6}$ The Kennedy Forum. A core set of outcome measures for behavioral health across service settings. 2015. http://thekennedyforumdot-org.s3.amazonaws.com/documents/MBC supplement.pdf

${ }^{7}$ Scott K, Lewis CC. Using measurement based care to enhance any treatment. Cognitive Behav Prac. 2015;22(1):49-59

${ }^{8}$ Skinner HA. The Drug Abuse Screening Test. Addict Behav. 1982; 7(4):363-371

${ }^{9}$ Elander J, Said O, Maratos FA, Dys A, Collins H, Schofield MB. Development and validation of a short-form Pain Medication Attitudes Questionnaire (PMAQ-14). Pain. 2017;158(3):400-407

${ }^{10}$ McCracken , LM, Hoskins J, Eccleston C. Concerns about medication and medication use in chronic pain. J Pain. 2006;7(10):726734. doi:10.1016/j.jpain.2006.02.014.

${ }^{11}$ Adams L, Gatchel R, Robinson R et al. Development of a self-report screening instrument for assessing potential opioid medication misuse in chronic pain patients. J Pain Symptom Manag. 2004;27:440-59

12 Butler SF, Fernandez K, Benoit C et al. Validation of the revised Screener and Opioid Assessment for Patients with Pain (SOAPP-R). J Pain. 2008;9(4):360-72

${ }^{13}$ Webster L, Webster R. Predicting aberrant behaviors in opioid-treated patients: preliminary validation of the Opioid Risk Tool. Pain Med. 2005;6:432-42

14 Jones T, Schmidt M, Moore T. Further validation of an opioid risk assessment tool: The Brief Risk Questionnaire. Ann Psychiatryt Ment Health. 2015;3(3):1032

15 Jones T, Lookatch S, Moore T. Validation of a new risk assessment tool: The Brief Risk Interview. J Opioid Manag. 2014;10:353-64

${ }^{16}$ Steenkamp M, Blessing E, Galatzer-Levy I et al. Marijuana and other cannabinoids as a treatment for posttraumatic stress disorder: A literature review. Depress Anxiety. 2017;34(3):207-16

${ }^{17}$ Blevins CA, Weathers FW, Davis MT et al. The Post Traumatic Stress Disorder Checklist for DSM-V(PCL-5): Development and initial psychometric evaluation. J Traumatic Stress.2015;28:489-98

18 National Center for PTSD. Clinician Administered PTSD Scale fir DSM-5 (CAPS-5). https://www.ptsd.va.gov/professional/assessment/adult-int/caps.asp

${ }^{19}$ Kroenke K, Spitzer RL, Williams JB. The PHQ-15: Validity of a new measure for evaluating the severity of somatic symptoms. Psychosom Med. 2002;64(2):258-66 
${ }^{20}$ Krupp LB, LaRocca NG, Muir-Bash J et al. The Fatigue Severity scale: applications to patients with multiple sclerosis and systemic lupus erythematosus. Arch Neurol. 1989;46:1121-3

${ }^{21}$ Schwartz JE, Jandorf L, Krupp LB. The measurement of fatigue: a new instrument. J Psychosom Res. 1993;37:753-62

${ }^{22}$ Kroenke K, Spitzer R, Williams JB. The PHQ-9: validity of a brief depression severity measure. J Gen Int Med. 2001;16:606-16

${ }^{23}$ Kroenke K, Spitzer R, Williams JBW et al. A brief measure for assessing generalized anxiety. Arch Int Med. 2006;166:1092-7

${ }^{24}$ EG Altman, D Hedeker, JL Peterson et al. The Altman Self-Rating Mania Scale. Biol Psychiatry. 1997;42: 948-955

${ }^{25}$ Shear MK, Brown TA, Barlow DH et al. Multicenter collaborative Panic Disorder Severity Scale. Am J Psychiatry. 1997;154:1571-75

${ }^{26}$ Bush K, Kivlahan D, McDonnell M et al. The AUDIT Alcohol Consumption Questions (AUDIT-C): An effective brief screening test for problem drinking. Arch Intern Med. 1998;3:1789-95

${ }^{27}$ Von Korff M, Ormel J, Keefe F et al. Grading the severity of chronic pain. Pain. 1992;50:133-49

${ }^{28}$ Von Korff M, Dunn K. Chronic pain reconsidered. Pain. 2008;138(2):267-76

${ }^{29}$ Bouhassira D, Attal N, Fermanian J et al. Development and validation of the neuropathic pain symptom inventory. Pain. 2004;108:248-57

${ }^{30}$ Portenoy R. Development and testing of a neuropathic pain screening questionnaire: ID Pain. Curr Med Res Opin. 2006;22(8):1555-65

${ }^{31}$ Freynhagen R, Baron R, Gockel U et al. painDETECT: a new screening questionnaire to identify neuropathic components in patients with back pain. Curr Med Res Opin. 2006;22(10):1911-20

${ }^{32}$ Bennett M, Smith B, Torrance N et al. The S-LANSS Score for identifying pain of predominantly neuropathic origin: Validation for use in clinical and postal research. J Pain. 2005;6(3):149-58

${ }^{33}$ Gudala K, Ghal B, Bansal D. Usefulness of four commonly used neuropathic pain screening questionnaires in patients with chronic low back pain: a cross-section study. Korean J Pain. 2017;30(1):51-8.

${ }^{34}$ Dawson J, Fitzpatrick R, Carr A et al. Questionnaire on the perceptions of patients about total hip replacement. Br J Bone Joint Surg. 1996;78-B(2):185-90

${ }^{35}$ Stewart WF. Validity of the Migraine Disability Assessment (MIDAS) Score in comparison to a diary-based measure in a population sample of migraine sufferers. Pain. 2000;88(1):41-52

${ }^{36}$ Aggarwal VR, Lunt M, Zakrzewska JM et al. Development and validation of the Manchester orofacial pain disability scale. Community Dent Oral Epidemiol. 2005;33:141-9

37 Jordan A, Manniche C, Modsal C rt al. The Copenhagen Functional Disability Scale: A study of reliability and validity. J Manipulative Physiol Ther. 1998;21(8):520-7

${ }^{38}$ Roach KE, Budiman-Mak E, Songsiridej N et al. Development of a shoulder pain and disability index. Arthritis Care Res. 1991;4(4):143-9

${ }^{39}$ MacDermids JC. Outcome evaluation in patients with elbow pathology: issues in instrument development and evaluation. $J$ Hand Ther. 2001;14:105-114 
40 MacDermid, JC. The Patient-Rated Wrist/Hand Evaluation. School of Rehabilitation Science, McMaster University 2009 http://www.srsmcmaster.ca/Portals/20/pdf/research resources/PRWHE.pdf

${ }^{41}$ Roland M, Morris R. A study of the natural history of low back pain: Part 1. Development of a reliable and sensitive measure of disability in low back pain. Spine. 1983;8:141-4

${ }^{42}$ Roland M, Fairbank J. The Roland_Morris Disability Questionnaire and the Oswestry Disability Questionnaire. Spine. $2000 ; 25(24): 3115-24$

${ }^{43}$ Litwin MS, McNaughton-Collins M, Fowler FJ et al. The National Institutes of Health chronic prostatitis symptom index: development and validation of a new outcome measure. Chronic Prostatitis Collaborative Research Network. 1999. J Urol;162(2):369-75

${ }^{44} \mathrm{Greco}, \mathrm{N}$. J., Anderson, A. F., Mann, et al. Responsiveness of the International Knee Documentation Committee subjective knee form in comparison to the Western Ontario and McMaster Universities Osteoarthritis Index, modified Cincinnati Knee Rating System, and Short Form 36 in patients with focal articular cartilage defects. Am J Sports Med. 2010; 38(5): 891-902.

${ }^{45}$ Frank L, Kleinman L, Farup C et al. Psychometric validation of a constipation symptom assessment questionnaire. Scand J Gastroenterol. 1999;34:870-7 